\title{
Management model based on agile methodologies for the execution phase of software projects
}

\author{
John Castillo,. Dario Amaya \\ Universidad Militar Nueva Granada \\ \{U21100025, dario.amaya\}@unimilitar.edu.co
}

\begin{abstract}
There are different methodologies and models for project management; however, the inadequate use of traditional methodologies admits the probability of presenting problems in the life cycle of the same, due to changes related to the cost, time or scope of the project. The objective of the study is to take advantage of the planning advantages of traditional methodologies, such as the PMI and to potentiate the execution and control phase, through the agile scrum methodology. To do so, the proposal and theoretical description of the model was made and validated, through the "Vulcano" software development project of the Colombian National Army. The verification made it possible to identify, that taking advantage of good planning and executing these projects with an agile methodology, generates satisfactory results for a software project. In this paper the results are presented based on the case study that provides this synergy of methodologies, where considerable advantages were found in a flexible execution, but involving daily task control.
\end{abstract}

Keywords: Management Model, agile methodology, traditional methodology, software development, planning, execution and control.

\section{INTRODUCTION}

One of the most valued and recognized models for project management at the international level is the PMI, with the guidance of the PMBOOK [1]. Despite being a very flexible and robust model, it has been found that its application in the execution and control phase of the projects can be reasonably deviated from the baseline[2] established during the project's start-up and planning phase.

The strong dependence, which is generated in the execution from the conventional methodologies, results in a weight that makes it difficult to cover the needs [3]. However, the misuse of methodological tools, traditional project management[4]presents problems related to the resources allocated.

In the areas of information technology, agile type PMOs have been implemented [5], considering that the conditions proposed by agile methodologies favor more efficient execution alternatives[6], since they favor the optimization of resources, and they include the expectations of the clients, adapting the processes to the different conditions of change.

In works such as those of Renie Dubs de Moya [7], it is identified that during the execution stage of the project, the control, evaluation and follow-up processes of each of the activities to be carried out are established, however some organizations present a scarce culture of monitoring and control, for projects [8], hindering decision-making and in turn affecting development processes.

In the environment, new hybrid techniques are born, as the DAC stands for Agile Development with Quality [9], allowing organizations to control costs and, in turn, ensure product quality; hand in hand with the client. This model has been based on practices of PMBOK, CMMI-DEV, ISO / IEC 12207, XP, Scrum, FDD and the agile Manifest [10].

A stage that is not very solid in most agile methodologies is the planning stage [11], which is very robust in the PMI model. In turn, the execution and control stage of the PMI model has several tools, but generally the conditions do not always turn out as planned, and there are important deviations from the baseline during the execution of the resources [4].

This paper proposes a model, applied to the software project management area, which implements the standard stages of the traditional PMI model, but adapts the agile scrum methodology, in the execution and control stage. To guarantee the execution with the active participation of the client, generating satisfactory results in a short time and facilitating the fulfillment of the objectives and plans.

\section{METHODS AND MATERIALS}

For the development of the model shown in Figure 1, the use of the tools offered by the PMBOOK guide is proposed, thus guaranteeing the life cycle of the project; placing special attention to the planning stage, so that, from the beginning, it can be established with a high degree of certainty, which resources will be necessary for the execution of the project. 


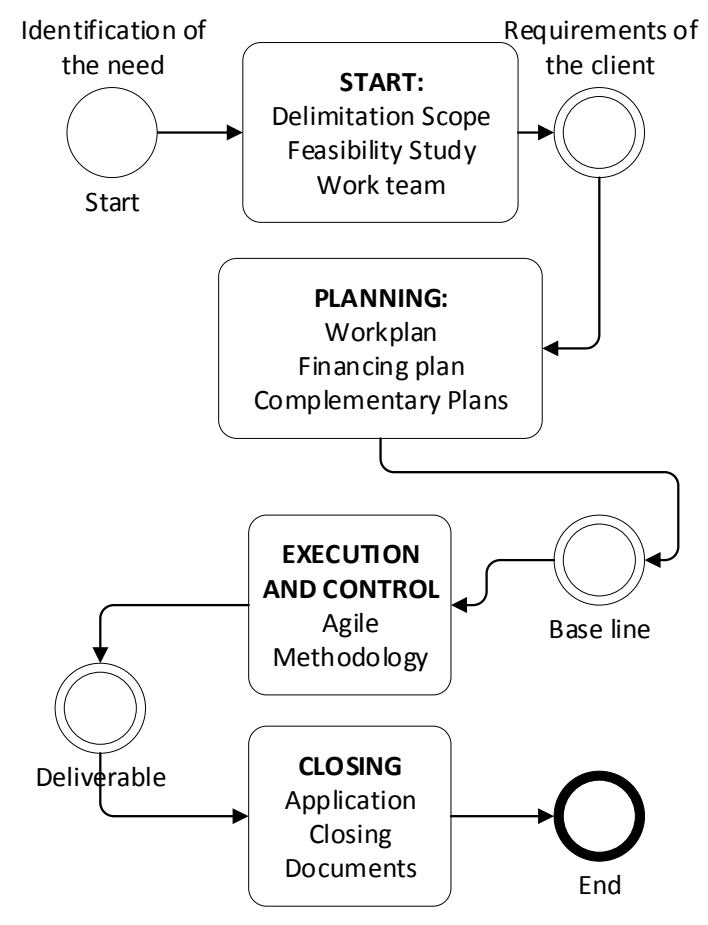

Figure 1General project structure for the model

The execution and control processes, which traditionally have actions and systems for monitoring schedules, specific planning tasks and strict progress reports, will be completely modified with the structure of the agile scrum methodology.

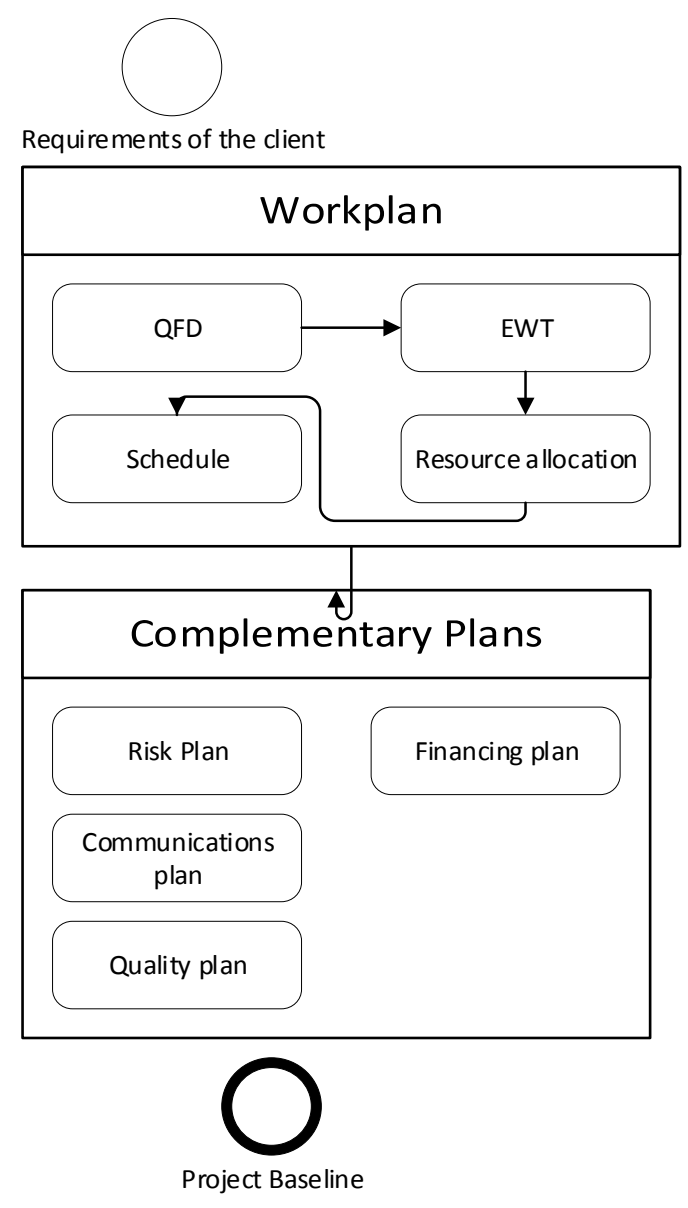

Figure 2 Planning stage of the model 
The stages of initiation and planning are conserved and applied enough to form a baseline of the project, in figure 2 the internal structure of this stage is shown in the model that considers the necessary resources and tentative timetables, which may result in global dates for the fulfillment of the milestones.

Based on this baseline, the implementation of the agile scrum methodology that is shown in the, for which the roles of client, Scrum master and development team must be established. The project manager plays the role of product owner, who receives the client's requirements, communicates them to the development team and defines the acceptance criteria for each cycle.

In the planning stage, a chronogram of times and milestones was generated, which should be considered in each of the cycles, making a direct association of the work packages with the objectives sought in each cycle. The intention is to avoid the advance of the tasks during extended times, that can misalign the individual developments, in front of the desired purpose for the deliverable.

All the components of the scrum cycle already known are applied [6], as shown in Figure 2. The control of resources is carried out by managing the items, with short time lapses, equivalent to each cycle. And taking control and execution to a more advanced level. In the daily meeting an update is made on the execution of each one of the works.

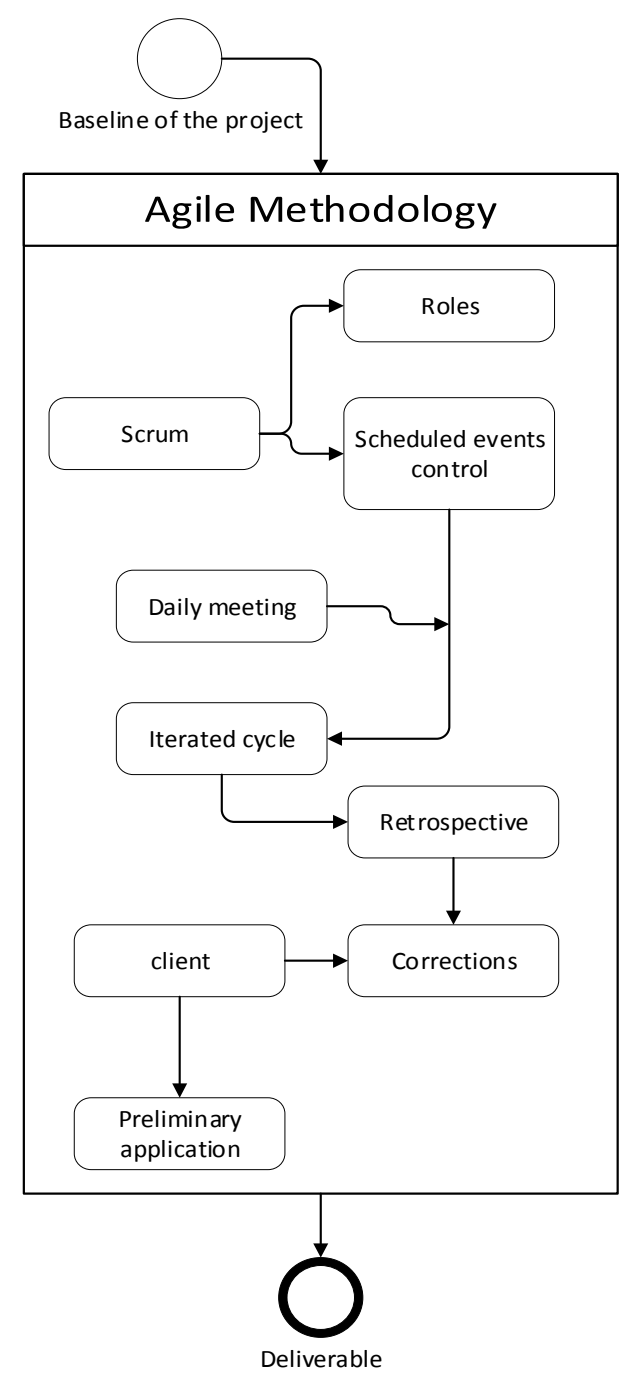

Figure 3 Stage of execution and control by scrum

Parallel to the tasks set for the developers, the integration and testing role must be defined within the development team, which has the responsibility of integrating the individual progress of the tasks into the software project, carrying out individual tests and planning the meetings with the clients, with the double purpose of verifying that the advances go in the desired direction and that the development adjusts to their needs.

At the end of the established cycles, the achievement of the work packages will be obtained, which in turn are aligned by the client's requirements. In this stage, the process of final verification and closure of the project begins, which now requires the necessary documentation, including all intellectual property reference issues. 


\section{Validation Case Study:}

\section{"Vulcano Software"}

\section{National Army Colombia}

The management model was implemented in the development of the "Vulcano" development project, which arose through a proposal of technology transfer of offset credits, which required for its approval, the structure of PMI, established for the stages of initiation and planning.

The objective of the Vulcano project was to develop software based on 3D cartography, which would allow planning for the Army's fire system, based on the requirements of users nationwide. All this based on the LUCIAD API.

Implemented for the execution and control stage, the agile scrum methodology, which in the first phase was raised with 30 specific requirements and were complied with in a span of 18 months, in which the work cycles were proposed each with a period of 5 days per week, in which the fire support coordinators were included, who would be the direct users of the product.

During the planning stage, 6 members of the development group were proposed, however, for the execution, only 05 members were counted, and the dedication times were not totally regular, considering other service obligations. However, the execution of the project was not affected since it was satisfactorily adapted by evaluating said limitations in each daily meeting and in each work cycle.

At the end of the technological development, the minimum viable product was obtained called: "Vulcano", which is in successful implementation within the military institution. The closing documents were made, and intellectual property protection procedures were initiated.

\section{ANALYSIS OF RESULTS}

Based on the case study, the execution of the project was monitored applying the model, evidencing that the execution of the work packages was clearly facilitated. As the problem statement showed, not all work packages were reached by the same planned human resources, since this resource is below $85 \%$ of available. The times also did not behave exactly according to the planning; however, all the objectives were reached in an even shorter time interval.

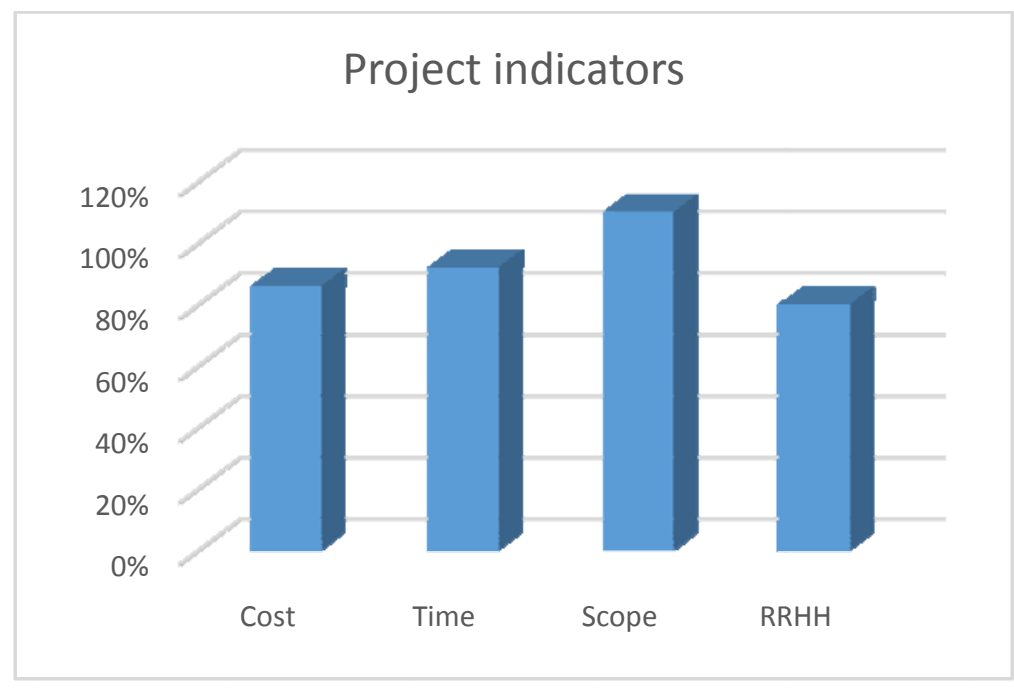

Figure 4 Percentages reached in the project indicators

Figure 4 shows the percentages used of resources of cost, time and human resources, likewise shows the percentage of reach obtained, which exceeds $100 \%$, considering that in the development were found new concepts that were implemented in the solution.

The acceptance level was evaluated by the development team, and their position in front of the model as shown in figure 5. Finding a satisfactory result, finding all the factors above $60 \%$. The lowest factor in the scale proposed was the knowledge received, where it is found that the work team perceives that the knowledge received in programming was just the necessary one. 


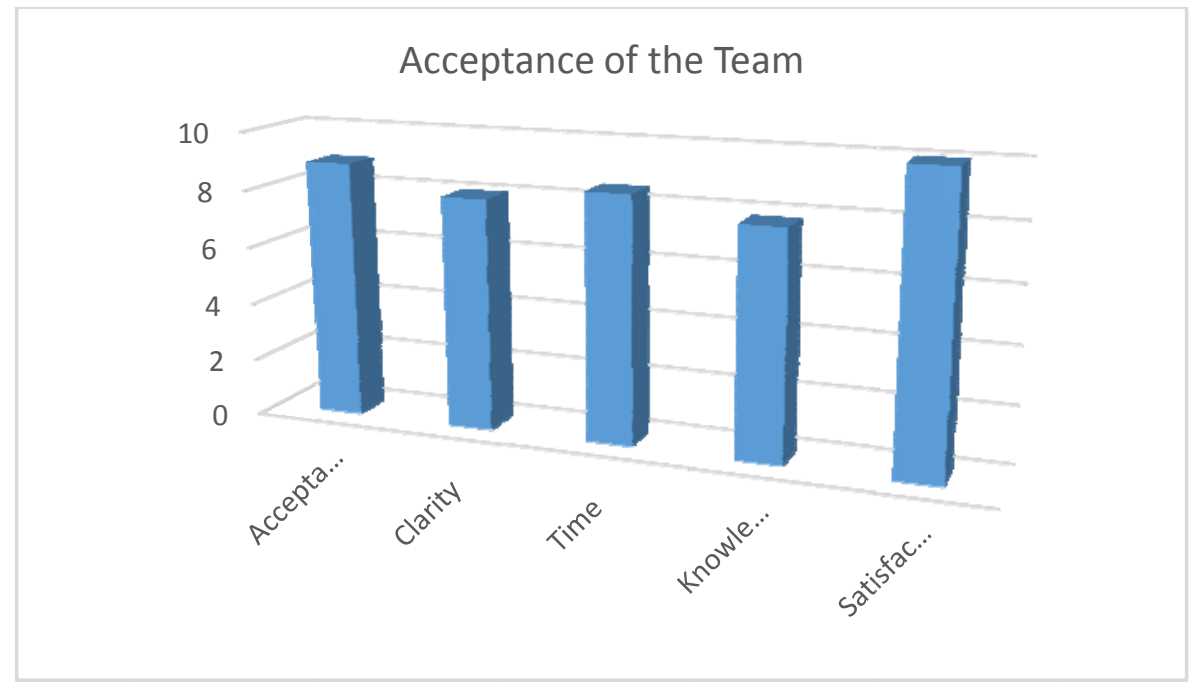

Figure 5 Acceptance level of the development team

On the other hand, the model was evaluated based on the delivered product and customer satisfaction, after the training and utilization process. The result is shown in Figure 6, Finding a satisfactory result in the final product, with a minimum of $70 \%$ acceptance, understanding that the project must go through a phase of continuous improvement and we see the possibility of adding new tools to development.

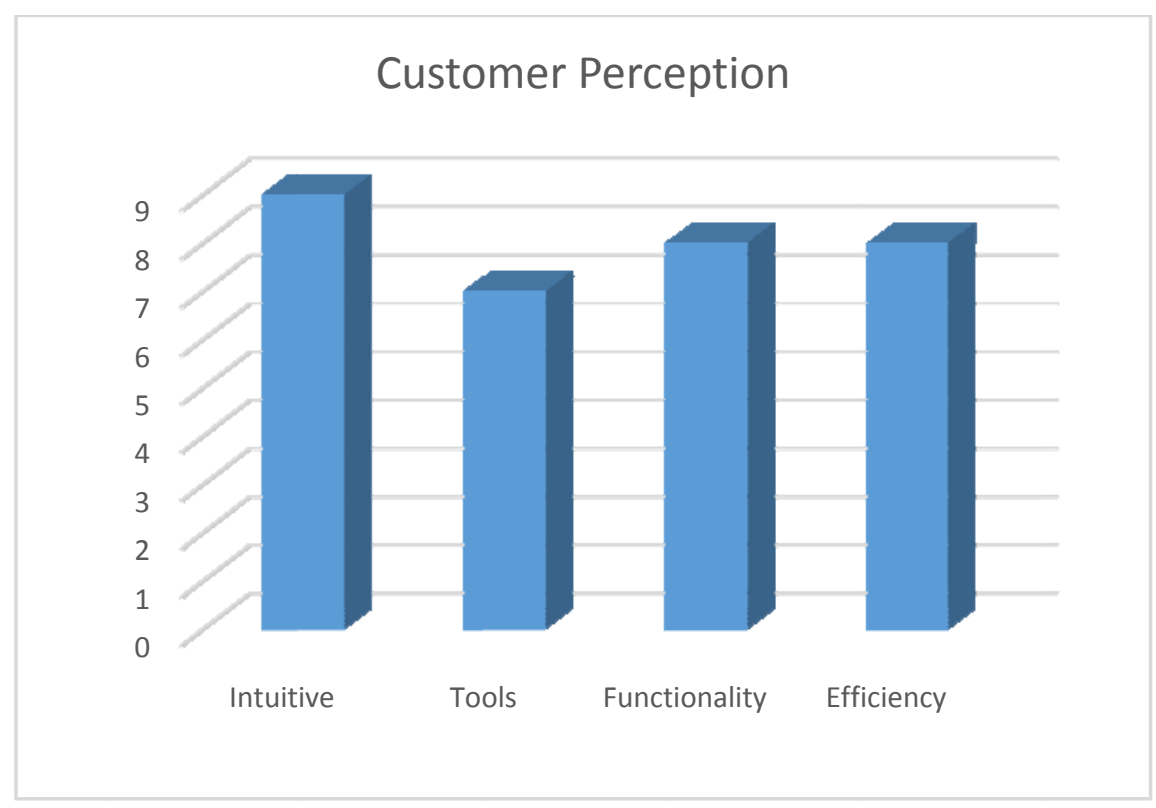

Figure 6Customer perception

\section{CONCLUSIONS}

The planning stage was fundamental for the proposed model, since the planned resources were sufficient for the execution, in addition to allowing its optimization.

The human resources assigned to the case study project, decreased to $85 \%$ of the planned, however, the model could solve this shortcoming to obtain the same result.

The development team showed a good acceptance of the model, since the control was carried out constantly, guaranteeing the alignment of its activities continuously.

The scrum methodology was valid from a good planning stage, otherwise if it had been executed alone, it would not have a clear starting point in terms of the allocation of resources. 


\section{REFERENCES}

[1] PMBOK, «Project Management Institute,» PMI® Internacional, Pensilvania (Estados Unidos), 2015.

[2] M. A. Cruz Cubillos, Análisis de mejoramiento de los capítulos PMI a través de metodología lean en el sector de construcción, Bogotá D.C: Universidad Militar Nueva Granada, 2015.

[3] S. G. R. Molina, Metodologías ágiles enfocadas al modelado de requerimientos, Rio Gallegos (Argentina): Universidad Nacional de la Patagonia Austral, 2014.

[4] C. M. y. L.-Z. R. G. Cuartas-Montoya, Aplicación de la metodología TOC al estándar PMI ®, Medellin, Colombia : Universidad EIA, 2014.

[5] D. Gómez González, Diseño e implementación de una PMO ágil para una pyme del sector de las Tecnologías de la Información y la Comunicación TIC, Bogotá: Universidad EAFIT, 2014.

[6] J. Z. Y. F. C. Victor Hugo Mercado-Ramos, Herramientas y buenas prácticas para el aseguramiento de calidad de software con metodologías ágiles, Sede central Tunja- Boyaca: UNIVERSIDAD PEDAGÓGICA Y TECNOLÓGICA DE COLOMBIA, 2015.

[7] R. D. d. Moya, El Proyecto Factible: una modalidad de investigación, Ciudad de Mexico: Instituto Pedagogico de Miranda, 2014.

[8] J. A. L. G. Jacqueline Marín Sánchez, Control de proyectos de software: actualidad y retos para la industria cubana, Santiago de Chile: Ingeniare Revista Chilena de Ingenieria, 2016.

[9] S. I. C. C. A. M. Marcela Alejandra Constanzo, Comparación de modelos de calidad, factores y métricas, Rio Gallegos (Argentina): Universidad Nacional de la Patagonia Austral, 2014.

[10] A. S. Méndez, MODELO Y PRÁCTICAS ESENCIALES DE LA METODOLOGÍA DAC INTEGRANDO LOS MÉTODOS ÁGILES, PMBOK Y CMMI-DEV, Medellin Colombia: Institución Universitaria Salazar y Herrera, IUSH - Centro de Investigación , 2014.

[11] N. G. Caso, SCRUM development process, Buenos Aires (Argentina): Universidad tecnologica Nacional de Buenos Aires, 2014.

[12] Prince2, What is PRINCE2?, London: https://www.prince2.com/usa/what-is-prince2, 2015.

\section{AUTHOR PROFILE}

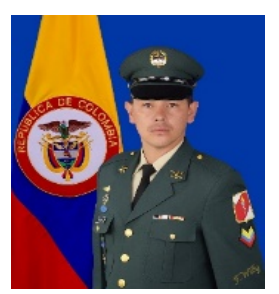

John Alexander Castillo Urrego (Born. 27 November1982). Mechatronics engineer UMNG. Student master's in project management. Non-commissioned fellow of the National Army of Colombia. Universidad Militar Nueva Granada.

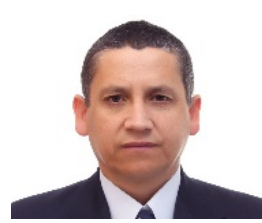

Dario Amqaya Hurtado, was born in Quimbaya, Quindio, Colombia. He was educated at Antonio Nariño University (UAN), Bogotá, Colombia, where he received the B Sc. degree in Electronics Engineering in 1995 and the M.Sc. degree in Tele informatics in 2007 by the Faculty of Engineering at Francisco José de Caldas District University (UFJC) in Bogotá, Colombia. He was awarded the Ph.D. 